\title{
Mineralization of Hydrogels for Bone Regeneration
}

\author{
Katerina Gkioni, M.Sc., ${ }^{1}$ Sander C.G. Leeuwenburgh, Ph.D., ${ }^{1}$ Timothy E.L. Douglas, Ph.D., \\ Antonios G. Mikos, Ph.D., ${ }^{2}$ and John A. Jansen, D.D.S., Ph.D.
}

Hydrogels are an important class of highly hydrated polymers that are widely investigated for potential use in soft tissue engineering. Generally, however, hydrogels lack the ability to mineralize, preventing the formation of chemical bonds with hard tissues such as bone. A recent trend in tissue engineering involves the development of hydrogels that possess the capacity to mineralize. The strategy that has attracted most interest has been the incorporation of inorganic phases such as calcium phosphate ceramics and bioglasses into hydrogel matrices. These inorganic particles act as nucleation sites that enable further mineralization, thus improving the mechanical properties of the composite material. A second route to create nucleation sites for calcification of hydrogels involves the use of features from the physiological mineralization process. Examples of these biomimetic mineralization strategies include (1) soaking of hydrogels in solutions that are saturated with respect to calcium phosphate, (2) incorporation of enzymes that catalyze deposition of bone mineral, and (3) incorporation of synthetic analogues to matrix vesicles that are the initial sites of biomineralization. Functionalization of the polymeric hydrogel backbone with negatively charged groups is a third mechanism to promote mineralization in otherwise inert hydrogels. This review summarizes the main strategies that have been developed in the past decade to calcify hydrogel matrices and render these hydrogels suitable for applications in bone regeneration.

\section{Introduction}

\section{Bone substitution materials}

B ONE IS A COMPOSITE MATERIAL comprised of a collagenous fibrous matrix that is enriched with platelet-shaped nanocrystals of carbonated apatite (average dimensions: $50 \mathrm{~nm}$ long, $25 \mathrm{~nm}$ wide, and $3 \mathrm{~nm}$ thick). This complex nanostructure makes bone a unique tissue with exceptional mechanical and biological properties. ${ }^{1,2}$

Despite several decades of research on synthetic bone substitutes, the use of autografts is still the gold standard in clinical practice. Autografting requires a surgery in which parts of healthy bone from the patient are harvested from, for instance, the iliac crest and subsequently transferred to the site of application. Alternative options include the use of bone harvested from another donor (allografts) or from animals (xenografts). ${ }^{3,4}$ Even though these surgical treatments have resulted into good clinical outcome, they are accompanied by strong drawbacks such as infections, pain, and morbidity at the donor site, high costs, and the necessity of additional surgery. ${ }^{5,6}$ To eliminate these severe problems, there is a pressing need for novel synthetic materials that can substitute bone sufficiently.

Several materials, such as metals ${ }^{7}$, ceramics, and polymers ${ }^{8}$, have been used for bone replacement. In the era of regenerative medicine, the poor degradability of metallic and ceramic scaffolds has become the major disadvantage that inhibits complete regeneration of bone tissue. Polymers, on the other hand, are known for the ease by which degradation can be tailored by controlling the chemical composition of the monomer units during synthesis. Until recently, the majority of polymeric bone substitutes were premade constructs that were implanted surgically via invasive surgery. Clinically, there is a growing need for materials that can be inserted using minimally invasive methods such as a simple injection. ${ }^{9}$ Ideally, such a material should be of viscosity low enough to be injected and harden after injection, thereby enabling incorporation of drugs, cells, and growth factors in the viscous solution before administration. ${ }^{10}$ Hydrogels are a specific, highly hydrated class of polymers that fulfill all of the abovementioned requirements.

\section{Hydrogels}

Hydrogels are hydrophilic crosslinked polymers that are formed by the reaction of one or more monomers, by association of hydrogen bonds or van der Waals interactions between the chains. ${ }^{11,12}$ The crosslinking can be achieved either physically or chemically. While in chemical crosslinking covalent bonds must be formed, physical crosslinking happens when physical interaction between the chains occurs. ${ }^{13}$

\footnotetext{
${ }^{1}$ Department of Biomaterials, Radboud University Nijmegen Medical Center, Nijmegen, The Netherlands.

${ }^{2}$ Department of Bioengineering, Rice University, Houston, Texas.
} 
Hydrogels can be classified according to their origin (natural or synthetic), ${ }^{14}$ method of preparation (homopolymer, copolymer, multipolymer, and interpenetrating hydrogels), ionic charges (neutral, anionic, cationic, and ampholytic hydrogels), and physical structure (amorphous, semicrystalline, and hydrogen bonded structures). ${ }^{11}$

When hydrogels are in contact with water, they swell and form an insoluble three-dimensional network. Other than injectability, hydrogels display many properties ${ }^{15}$ that make them desirable candidates for tissue engineering applications. One of the most important advantages is their aqueous environment, which protects cells and sensitive drugs that can be incorporated in the network for controlled delivery at the site of injury. The aqueous environment allows transportation of substances, such as nutrients and by-products from cell metabolism, in and out of the hydrogels. ${ }^{16} \mathrm{Hy}-$ drogels can also be derivatized with functional groups that mediate processes such as cell attachment and subsequent spreading. ${ }^{17}$ Until recently, hydrogels have been mainly considered for soft tissue regeneration. In the last few years, however, the interest to test the feasibility of using the beneficial properties of hydrogels for hard tissue regeneration has increased. Still, for applications in hard tissue engineering, hydrogels are associated with a number of disadvantages such as their poor mineralization upon implantation. ${ }^{18}$ Further, the inherent mechanical weakness of hydrogels is a limiting factor that restricts their use to non-load-bearing applications ${ }^{15,19}$, even though reinforcement can be achieved by the addition of other phases. ${ }^{6,18,20,21}$ Finally, many hydrogels are difficult to sterilize due to their high water content and the polymer reactivity under UV light. ${ }^{22}$

It is not in the scope of this study to review a list of all the hydrogels-natural or synthetic-used in the field of tissue engineering, since there are many excellent reviews that thoroughly elaborate on this subject. ${ }^{19,23-28}$ This article will focus on the strategies developed during the past decade to induce mineralization in inert, nonmineralizing hydrogels in vitro (immersion in simulated body fluids [SBF]) or in vivo for use in bone regeneration. Three major strategies used for calcification of hydrogels will be reviewed, including (1) the addition of inorganic particles aiming at mineralization and improvement of the mechanical properties of hydrogels, (2) the creation of nucleation sites by biomimetic methods, such as soaking treatments and the use of enzymes and vesicles that play an important role in physiological biomineralization, and (3) the derivatization of the polymeric hydrogel backbone with anionic functional groups. In addition, some indirect methods of mineralization such as growth factors and cell incorporation or addition of demineralized bone matrix will be briefly discussed.

\section{Mineralization by Adding Inorganic Phases}

The capacity of a specific class of bone-substituting materials to induce calcification is often referred to as bioactivity, which implies that these materials possess the capacity to promote nucleation and subsequent proliferation of calcium phosphate crystals. Generally, most polymeric materials do not possess this capacity, but the addition of a ceramic phase can still render the resulting composites bioactive by providing nucleation sites for the promotion of hydroxyapatite (HA) precipitation. The concept of combining a hydro- gel with an inorganic phase is inspired by the composite nature of bone itself. One of the many advantages of adding an inorganic phase is that the dispersed mineral will provide nucleation sites for HA formation as well as cell adhesion sites that enable integration with surrounding bone tissue. ${ }^{29,30}$ Further, degradation of the temporary hydrogel implant will allow for replacement by new bone formation, thus increasing mechanically stability.

Degradation times and mechanical properties of organicinorganic composite materials can be controlled to a large extent by the addition of inorganic phases. ${ }^{20,21,31}$ Moreover, the handling characteristics of such composite materials can be greatly improved, since brittle ceramic particles can be delivered in moldable or even injectable formulations using the elasticity of the hydrogels. ${ }^{5}$ Finally ${ }^{32}$, the addition of carbonated apatites in polymers can have a neutralizing effect on the acidic $\mathrm{pH}$ caused by the degradation by-products, thus minimizing excessive inflammation around the implantation site.

There are many bioactive inorganic materials that can be used to render hydrogels mineralizable. These ceramic materials are able to create a firm bond with bone at the site of implantation by forming an intermediate layer of $\mathrm{HA}$ on their surface. ${ }^{33}$

The most commonly used inorganic phases are calcium phosphates and bioglasses. Many calcium phosphate ceramics can be found in literature with the most representative being $\beta$-tricalcium phosphate $(\beta-\mathrm{TCP})$, amorphous calcium phosphate, and HA. This group of ceramics shows strong resemblance to the mineral phase of bone and it is found in many normal or pathological calcified sites in the human body. ${ }^{34}$ Thorough reviews of all relevant calcium phosphates that are present in the human body can be found elsewhere. ${ }^{35-37}$ Bioactive glasses are amorphous solids containing $<60 \mathrm{wt} \% \mathrm{SiO}_{2}$ that are bioactive due to their high reactivity in aqueous media. Modern preparation techniques such as the sol-gel process have yielded a wide range of mesoporous, highly bioactive, and bioresorbable materials for the production of bone implants. ${ }^{38}$ It has been shown ${ }^{39,40}$ that the formation of HA on the surface of these materials is due to the formation of $-\mathrm{OH}$ groups when the glass contacts body fluids. ${ }^{41,42}$

\section{Composites based on natural hydrogels}

Advantages of natural hydrogels include their biocompatibility, biodegradability, and commercial availability. Composites of natural hydrogels and bioactive phases have been shown to accelerate osteogenesis and sometimes possess osteoconductive properties that were even superior to monolithic HA implants. ${ }^{43}$ There are many natural polymers ${ }^{23}$ used for tissue engineering most commonly collagen and its denatured derivative gelatin ${ }^{44}$, fibrin, as well as chitin and its deacetylated derivative chitosan.

Collagen (mostly collagen type I) is the main polymer phase of bone, ${ }^{45}$ and it is highly biocompatible, degrades enzymatically, and can be processed easily into different forms such as sponges, ${ }^{46}$ fibers, ${ }^{47}$ tubes, and sheets. ${ }^{48,49}$ An example of a collagen hydrogel that was combined with an inorganic calcium phosphate phase was reported by Zou et al. ${ }^{49}$ The collagen fibers were crosslinked by using glutaraldehyde. Ceramic $\beta$-TCP particles were homogeneously 
dispersed inside the collagen matrix, but also a firm bond between the ceramic particles and the hydrogel was formed. In addition, the scaffolds showed bone tissue regeneration after 12 weeks of implantation in animals. For more specific information on the use of collagen as matrix phase, the reader is referred to a thorough review about collagenHA composites for hard tissue engineering by Wahl and Czermuszka. ${ }^{50}$

Fibrin glue ${ }^{51,52}$ is a synthetic analogue of the blood coagulation process that creates a fibrin clot upon mixing of the two components fibrinogen and thrombin and it can be used as tissue adhesive in many surgical applications due to its favorable biological behavior. Le Nihouannen et al. ${ }^{53}$ combined these beneficial properties of fibrin glue in terms of clinical handling and biocompatibility with the bioactive characteristics of an additional ceramic phase to develop a composite material for bone regeneration. Micro- and macroporous biphasic calcium phosphate granules (HA and $\beta$-TCP in a weight ratio of $60 / 40$, respectively) were mixed with a fibrin glue matrix inducing mineralization within the fibrin network.

Tan et al..$^{54}$ prepared an injectable biomaterial consisting of calcium alginate and nano-HA. The injectability and the setting time of the material could be easily tuned by altering the absolute and relative concentrations of the components. Alginate has the unique capacity to gel in the presence of dissolved calcium ions, which is a very mild method to create crosslinks into an organic matrix. The particles of HA had a diameter of $50 \mu \mathrm{m}$ and the final concentration of $\mathrm{HA}$ in the gel was kept at $3 \% \mathrm{~g} / \mathrm{mL}$. $\mathrm{CaSO}_{4}$ was used to crosslink the alginate gel. It was concluded that that the final composite material is a good candidate for bone repair and bone tissue engineering. Alginates for bone reconstruction reinforced with $\mathrm{HA}^{55}$ and octacalcium phosphate ${ }^{56}$ have also been shown to be bioactive.

Addition of $\mathrm{SiO}_{2}$, which is the main component of bioglasses, inside polymeric matrices also aims to trigger the calcification of polymer matrix. Madhumathi et al. ${ }^{57}$ prepared a scaffold by dispersing silica nanoparticles inside a chitin hydrogel. The scaffold showed HA formation only after 7 days of immersion in SBF. Similar particles were also introduced inside chitosan hydrogels ${ }^{58}$ and significant mineralization of the matrix was observed after immersion in SBF as well as implantation in rat calvaria for 3 weeks. Similarly, addition of sol-gel prepared $\mathrm{SiO}_{2}-\mathrm{CaO}-\mathrm{P}_{2} \mathrm{O}_{5}$ bioglass nanoparticles inside a chitosan-based hydrogel also induced bone-like apatite after immersion in SBF. ${ }^{59}$

\section{Composites based on synthetic hydrogels}

Even though naturally derived hydrogels have desirable biological properties, they often exhibit degradation profiles that are too fast for hard tissue regeneration. ${ }^{60}$ Moreover, chemical characteristics of natural hydrogels such as the molecular weight usually display a wide distribution due to their natural origin, which limits the reproducibility and functionality of the materials. On the contrary, synthetic hydrogels can be prepared with tailored and highly reproducible chemical characteristics, thereby allowing for careful degradation properties. ${ }^{61}$ The combination of the different monomer units results in hydrogels with controlled characteristics in terms of degradation rate, swelling ratios, and mechanical properties. ${ }^{62}$
Polymeric chains can be finely tuned based on the clinical requirements of the various applications in hard tissue engineering. As a result, a wide range of crosslinking techniques can be used to form the hydrogels such as photopolymerization or radical polymerization in the presence of small crosslinking agents. ${ }^{10,17,61}$ The most common synthetic hydrogels that are studied for bone tissue engineering purposes include hydrogels based either on polyethylene glycol (PEG) $^{62,63}$, poly(2-hydroxyethyl methacrylate) (pHEMA), or poly(N-isopropylacrylamide). ${ }^{64,65}$

A recent example of the use of PEG-based hydrogels as matrix for the addition of inorganic HA nanoparticles was described by Sarvestani et al., ${ }^{66,67}$ who exploited the calciumbinding capacity of a 6-glutamic acid sequence (as found in the terminal sequences of osteonectin) to increase the interaction strength between inorganic HA nanoparticles and (L-lactide-co-ethylene oxide-co-fumarate). The other end of the peptide was functionalized with an acrylate group that enabled the establishment of covalent bonds between the peptide and the organic polymer. In this way, the functionalized peptide acted as a linker between inorganic and organic composite components.

Patel $e t$ al. ${ }^{68}$ developed cyclic acetal hydrogels reinforced with nanoparticles of HA for craniofacial tissue engineering application. Incorporation of HA nanoparticles into cyclic acetal hydrogels resulted into enhanced differentiation of bone marrow stromal cells by promotion of endogenous osteogenic signal expression.

Composites based on pHEMA with high mineral content of about $37 \%-50 \%$ were prepared by Song et al. ${ }^{69}$ The group used pHEMA polymer that was crosslinked in the presence of HA crystals using viscous ethylene glycol as solvent to facilitate the easy dispersion and prevent sedimentation of the HA particles. Even though the material had a mineral content similar to that of human bone, it possessed elastomeric properties that allowed for press-fitting the composites into bone defects. After implantation in rats, the material supported osteoblastic differentiation and promoted bone mineralization. The combination of the excellent mechanical properties along with the beneficial biological response, confirm the promising concept of using pHEMA in combination with HA crystals. Similarly, pHEMA has been reinforced with inorganic particles such as such as $\mathrm{TiO}_{2}$ nanoparticles, ${ }^{70}$ nanocarbonate-substituted apatite, ${ }^{71}$ and $\mathrm{SiO}_{2}$ nanoparticles. ${ }^{72}$

\section{Biomimetic Mineralization}

Hydrogels can also be mineralized by means of biomimetic methods that take their inspiration from the biomineralization process by which native apatite nanocrystals are formed in vivo. Several features from this biomineralization process have been studied for their potential to be used in hydrogel mineralization, including (alternate) soaking treatments in fluids that are saturated with respect to apatite deposition, enzyme-directed mineralization, and the incorporation of synthetic analogs of matrix vesicles as initial sites of biomineralization.

\section{Soaking in solutions containing $\mathrm{Ca}^{2+}$ and $\mathrm{PO}_{4}{ }^{3-}$}

$\mathrm{Du}$ et al. ${ }^{73}$ used collagen matrices presoaked in $\mathrm{PO}_{4}{ }^{3-}$ that were subsequently immersed in $\mathrm{Ca}^{2+}$ solutions. By 
controlling the parameters of their method, different crystal polymorphs could be created, whereas the materials were shown to be able to promote mineralization upon implantation in rats. Furuichi et al. ${ }^{74}$ prepared a calcium phosphatepolyacrylic acid composite hydrogel by crosslinking a polyacrylic acid polymer in the presence of $\left(\mathrm{NH}_{4}\right) \mathrm{HPO}_{4}$ solution and then immersing it in a calcium containing solution. The diffusion of $\mathrm{Ca}^{2+}$ into the polyacrylic acid hydrogel that contained phosphate ions induced calcification of the hydrogel matrix resulting in a hierarchically organized composite architecture that resembled bone.

By alternately incubating a cellulose hydrogel in calcium and phosphate solutions, Hutchens et al. ${ }^{75}$ was able to prepare biomimetic composites. The mineral phase of these composites was characterized as calcium-deficient HA. X-ray diffraction also revealed that the crystallites formed were elongated along the c-axis and had a length of $\sim 50 \mathrm{~nm}$, which is similar to the apatite crystals found in natural bone. The same mechanism was utilized to induce HA mineralization in a chitosan hydrogel by Madhumathi et al.,${ }^{76}$ who used chitosan hydrogel membranes that were alternately soaked in solutions of $\mathrm{CaCl}_{2}$ and $\mathrm{Na}_{2} \mathrm{HPO}_{4}$. HA deposits were homogeneously dispersed throughout the matrix after five cycles. Similarly, Hong et al. ${ }^{77}$ used a cellulose hydrogel that was first treated with a $\mathrm{CaCl}_{2}$ solution and then immersed in SBF. Uniform and dense biomimetic mineralization was observed after immersion for 14 days in the SBF solution.

Using a urea-containing solution, Kim et al. managed to precipitate calcium phosphate crystals on top and inside a PEG-based hydrogel. ${ }^{78}$ The PEG-fumarate polymer was crosslinked with ethylene glycol methacrylate phosphate, which acted as a source of phosphorous for the formation of apatitic crystalline platelets with a ratio of $\mathrm{Ca} / \mathrm{P}$ equal to 1.60 .

\section{Vesicles loaded with $\mathrm{Ca}^{2+}$ and $\mathrm{PO}_{4}^{3-}$}

Another aspect of bone biomineralization that has been exploited to calcify hydrogel matrices relates to the vesicular nature of physiological calcification. Initial mineralization occurs in the so-called matrix vesicles, which are cellularly derived structures of $40-200 \mathrm{~nm}$ in diameter that are separated from other structures in the extracellular matrix by a limiting phospholipid membrane enclosing a central aqueous core. After their formation in specific regions of the outer membrane of osteoblasts, these vesicles migrate toward the calcification front of growing bones. Here, the vesicles secrete apatitic crystals that subsequently calcify periodically arranged, calcium-binding hole zones with specific amino acid composition in collagen fibers of the extracellular matrix. ${ }^{79,80}$ Liu et al. ${ }^{81}$ created liquid vesicles that entered the hydrogel matrix using a current-mediated ion diffusion method that resulted in mineralization at the interior of a pHEMA hydrogel. The dense hydrogel acted as binding site for the Ca ions and promoted mineralization of nanoapatite. The mineral that was formed inside the entire volume of the hydrogel exhibited a structure very similar to the inorganic component of bone. A similar strategy to promote mineralization according to vesicular mineralization was developed by Pederson et al. ${ }^{82}$ and Westhaus and Messersmith. ${ }^{83}$ In the latter studies the vesicles were designed to melt at body temperature to release the $\mathrm{Ca}^{2+}$ and $\mathrm{PO}_{4}{ }^{3-}$ ions necessary for mineralization of the surrounding hydrogel matrix.

\section{Enzymatic mineralization}

Alkaline phosphatase (ALP) ${ }^{84}$ is an enzyme that plays an important role in the remodeling of bone and more specifically in the resorption of bone and the mineralization of carbonated apatite. The enzyme acts as a catalyst for the hydrolysis of the organic phosphoesters, thereby increasing the local concentration of inorganic phosphate groups that results into enzyme-directed deposition of carbonated apatites. ${ }^{85,86}$ Moreover, ALP decreases the concentration of pyrophosphates that act as inhibitors of apatite crystal growth. Recently, several groups have tried to immobilize this enzyme onto implant surfaces or into hydrogels to induce local mineralization of implant surfaces and scaffolds. ${ }^{87}$

ALP has been immobilized ${ }^{88}$ onto a fibrin gel by activating the $-\mathrm{COOH}$ groups from fibrin glue using 1-ethyl-3-(dimethylaminopropyl) carbodiimide hydrochloride. Subsequently, these scaffolds were incubated in ALP solutions resulting in covalent bonding between the enzyme and the fibrin scaffold. Using a mouse calvarial defect model, it was demonstrated that the fibrin scaffold with the immobilized ALP enhanced new bone formation.

Similarly ${ }^{89}$, ALP has been immobilized onto a pHEMA hydrogel using a copolymerization technique. The enzyme retained its activity after copolymerization, and after immersion in SBF containing organophosphates for 17 days, mineral deposition was observed.

Spoerke et al. ${ }^{90}$ report the synthesis of a novel gel composed of amphiphilic nanofibers functionally enriched with phosphorylated and acidic groups. The hydrogels were formed in the presence of cell culture media supplemented with calcium chloride and immersed in calcification media containing $\beta$-glycerolphosphate and ALP among others. After 8 days of immersion the mineralization was visibly apparent throughout the hydrogel.

\section{Chemical Modification of Hydrogels}

A different approach to induce mineralization in hydrogels involves the introduction of negatively charged functional groups onto the backbone or side chains of hydrogel polymers. This mechanism resembles the biomineralization process in bone tissue, where noncollagenous, calcium-binding proteins are essential as modulators of nucleation and growth of apatitic biomineral nanocrystals. Generally, these proteins are acidic and phosphorylated and accumulate in mineralizing bone matrix ${ }^{91}$. Important mineral-inducing proteins such as osteonectin and bone sialoprotein (BSP) are enriched in anionic glutamate (Glu). ${ }^{92,93}$ These acidic sequences are responsible for the attraction of $\mathrm{Ca}^{2+}$ and subsequent creation of a local supersaturation that is necessary for $\mathrm{CaP}$ precipitation, which make them quintessential for biomineralization of hard tissues. Similarly, alternating sequences of anionic carboxylate, phosphate, or hydroxyl groups along the backbone of synthetic or natural polymers can endow the resulting hydrogels in swollen state with apatite-nucleating properties. Therefore, the implementation of acidic sequences into hydrogels opens up new perspectives for the development of hydrogels with mineral-attracting capacity. The following section will address the functionalization of hydrogels with negatively charged groups $\left(\mathrm{PO}_{4}{ }^{3-}, \mathrm{COOH}\right.$, and $\left.\mathrm{OH}\right)$ that are either present as isolated functional groups or as part of peptide sequences. 


\section{$\mathrm{PO}_{4}{ }^{3-},-\mathrm{COOH}$, and $-\mathrm{OH}$ groups}

Addition of negatively charged groups such as phosphate, carboxylate, and hydroxyl groups is commonly performed by copolymerization of the hydrogel-forming polymer with monomers containing one or more of these groups.

Stancu et al. ${ }^{94}$ developed copolymers of diethyl amino ethyl methacrylate and methacryloyloxyethyl phosphate (MOEP), as well as copolymers of MOEP with 1-vinyl-2pyrrolidinone and compared the calcification ability of both types of copolymer. Samples with different phosphate content were prepared and immersed in SBF for 15 days. The results revealed that globular mineralization occurred on the surface of the MOEP-diethyl amino ethyl methacrylate hydrogels. The absence of mineral deposition onto the MOEP1-vinyl-2-pyrrolidinone copolymers was attributed to the fact that each calcium ion was double bonded by two phosphate groups from adjacent MOEP units formed during copolymerization.

Nuttelman et al. ${ }^{95}$ coupled ethylene glycol methacrylate phosphate groups to PEG-diacrylate hydrogels. The polymers were immersed in human mesenchymal stem cell culture media that were supplemented with $\beta$-glycerophosphate, which resulted in mineral formation on their surface. The precipitated mineral was found to resemble biological apatites not only in composition, but also in molecular structure. Wang et al. ${ }^{96}$ also modified a PEG hydrogel by copolymerization with a phosphoester. Upon immersion in osteogenic media for 3 weeks, extensive mineralization was observed throughout the three-dimensional network of the copolymer.

The introduction of carboxymethyl groups on the pHEMA backbone was described by Filmon et al. ${ }^{97,98}$ The prepared carboxylated scaffolds were immersed in SBF supplemented with antibiotics for 15 days. The results showed that mineralization was induced only by the functionalized pHEMAcarboxymethyl hydrogel, whereas the unfunctionalized pHEMA hydrogels did not display any mineral formation. Crosslinked pHEMA has also been modified by exposing carboxylate groups on the surface of the hydrogel using urea to hydrolyze the 2-hydroxyethyl esters of the polymer by Song et al., ${ }^{99}$ who also prepared libraries of pHEMA-based hydrogels ${ }^{100}$ copolymerized with negatively charged monomers in a separate study. Both types of carboxylate-functionalized hydrogels were reported to induce mineralization after immersion in SBF.

The introduction of hydroxyl-containing silanol (Si-OH) groups on thermosensitive poly(N-isopropylacrylamide)PEG dimethacrylate copolymer is described by Ho et al. ${ }^{101}$ These silanol groups were introduced to the main polymer backbone by reacting with trimethacryloxypropyltrimethoxysilane (MPS). It was reported ${ }^{102}$ that MPS could be added at various concentrations, thereby improving the mechanical properties of the final hydrogel without altering its lower critical solution temperature. Similar to carboxylate and phosphate groups, $\mathrm{Si}-\mathrm{OH}$ groups present in MPS provided sites that bound calcium and induced subsequent mineral deposition upon soaking in SBF.

\section{Peptide-mediated mineralization-acidic peptides}

Acidic peptide sequences can be conjugated on a hydrogel, but there are also formulations of hydrogels composed of polymerized polypeptides. The mineralization capacity of a hydrogel made from crosslinked polyglutamic acid was studied by Sugino et al. ${ }^{103}$ The hydrogel samples studied were injectable and bioresorbable, and after crosslinking they were treated with different concentrations of $\mathrm{CaCl}_{2}$ solutions for $24 \mathrm{~h}$ at body temperature. Upon soaking in SBF for 7 days, HA was formed on the surface of the treated hydrogels irrespective of the $\mathrm{CaCl}_{2}$ concentration of the solution used for the pretreatment.

The HA nucleation potency of BSP-collagen hydrogels was tested and compared with agarose-BSP gels by Baht et al. ${ }^{104}$ To assess the mineralization potency, the hydrogel scaffolds were perfused with buffers containing either $\mathrm{Ca}\left(\mathrm{NO}_{3}\right)_{2}$ or $\mathrm{Na}_{2} \mathrm{HPO}_{4}$ with a steady flow state. The results showed that collagen favors the BSP nucleation potency by nearly a factor of 10 when compared to agarose gels. The synergistic interaction between collagen and BSP appeared to improve the mineralization capacity of these natural hydrogels.

Chirila et al. ${ }^{105}$ immobilized three different artificial protein sequences onto pHEMA hydrogels. These sequences (two of them can be found in nacrein and the third is present in dentin matrix acidic phosphoprotein) were tested in vitro and their ability to nucleate calcium phosphate was assessed in solutions. Disks prepared from the peptide conjugated polymers were immersed in $\mathrm{Ca}^{2+}$ and $\mathrm{PO}_{4}{ }^{3-}$ containing media for a total period of 6 weeks. The peptide sequences were shown to have no or an enhancing effect on calcium mineralization.

Gungormus et al. ${ }^{106}$ developed a peptide-based hydrogel that mediated the formation of HA. The 27 residue peptide MDG1 self-assembles into a hydrogel by changing its form when alternating the ionic strength of the solution. By entrapping ALP in the hydrogel and immersing it in a $\beta$-glycerophosphate solution, mineralization of the hydrogel was achieved.

\section{Indirect Mineralization}

Even though it is not the scope of this review to address drug or cell delivery systems, it should be emphasized that hydrogels are often used to deliver osteoinductive growth factors such as bone morphogenetic proteins, demineralized bone matrix, ${ }^{107-114}$ and/or cells, ${ }^{115-125}$ and in many of these cases extensive mineralization is observed as a secondary consequence. According to this mechanism, growth factors trigger cell signaling pathways that stimulate stem cells in the direct vicinity of the hydrogel to differentiate into the osteogenic lineage and produce biomineral. In the case of cell delivery, cells that have been differentiated into the osteogenic lineage are encapsulated directly into hydrogels before implantation that subsequently calcify the carrier hydrogel.

Introduction of the Arginine-Glysine-Aspartate amino acid sequence (RGD or Arg-Gly-Asp) is commonly used to provide attachment and differentiation sites for cells inside the hydrogels resulting in indirect mineralization. ${ }^{126-128}$

For further information on mineralization induced by growth factors release and/or cell encapsulation, the reader is referred to reviews by Salinas and Anseth, ${ }^{123}$ Hunt and Grover, $^{129}$ and Schmidt et al. ${ }^{130}$

\section{Conclusions}

Traditionally, hydrogels have been considered for soft tissue regeneration only, but recently successful attempts have been made to render hydrogels suitable for hard tissue 
regeneration. The highly hydrated nature of hydrogels offers significant advantages over conventional ceramics and nonswelling polymers in terms of biocompatibility, biodegradation, drug delivery, and injectability that have not been exploited so far. Since bone is a highly mineralized tissue, the lack of mineralization ability of inert hydrogels can be generally considered as the major stumbling block toward application of hydrogels for bone-substituting purposes. This review provides an overview of recent strategies that have been explored to calcify hydrogels, including the addition of bioactive inorganic phases, biomimetic mineralization pathways that adopt principles from biomineralization, and the functionalization of hydrogels with negatively charged functional groups.

\section{Acknowledgments}

The authors gratefully acknowledge the support of the Smart Mix Program of the Netherlands Ministry of Economic Affairs and the Netherlands Ministry of Education, Culture and Science.

\section{Disclosure Statement}

No competing financial interests exist.

\section{References}

1. Rho, J.Y., Kuhn-Spearing, L., and Zioupos, P. Mechanical properties and the hierarchical structure of bone. Med Eng Phys 20, 92, 1998.

2. Weiner, S., and Wagner, H.D. THE material bone: structure-mechanical function relations. Annu Rev Mater Sci 28, 271, 1998.

3. Burg, K.J.L., Porter, S., and Kellam, J.F. Biomaterial developments for bone tissue engineering. Biomaterials 21, 2347, 2000.

4. LeGeros, R. Properties of osteoconductive biomaterials: calcium phosphates. Clin Orthop Relat Res 395, 81, 2002.

5. Kretlow, J.D., and Mikos, A.G. Review: mineralization of synthetic polymer scaffolds for bone tissue engineering. Tissue Eng 13, 927, 2007.

6. Khan, Y., Yaszemski, M.J., Mikos, A.G., and Laurencin, C.T. Tissue engineering of bone: material and matrix considerations. J Bone Joint Surg Am 90, 36, 2008.

7. Niinomi, M. Metallic biomaterials. J Artif Organs 11, 105, 2008.

8. Zhou, Z., Liu, X., Liu, Q., and Liu, L. Evaluation of the potential cytotoxicity of metals associated with implanted biomaterials (I). Prep Biochem Biotechnol 39, 81, 2009.

9. Kohane, D.S., and Langer, R. Polymeric biomaterials in tissue engineering. Pediatr Res 63, 487, 2008.

10. Nguyen, M.K., and Lee, D.S. Injectable biodegradable hydrogels. Macromol Biosci 10, 563, 2010.

11. Peppas, N. Hydrogels. In: Ratner, B.D., Hoffman, A.S., Schoen, F.J., and Lemons, J.E., eds. Biomaterials Science: An Introduction to Materials in Medicine. Amsterdam: Elsevier Academic Press, 2004, pp. 100-107.

12. Hillel, A., Shah, P., and Elisseeff, J. Hydrogels in cell encapsulation and tissue engineering. In: Jenkins, M. ed. Biomedical Polymers. Cambridge, England: Woodhead Publishing Ltd., 2007, pp. 57-75.

13. Hennink, W.E., and van Nostrum, C.F. Novel crosslinking methods to design hydrogels. Adv Drug Deliv Rev 54, 13,2002
14. Klouda, L., and Mikos, A.G. Thermoresponsive hydrogels in biomedical applications. Eur J Pharm Biopharm 68, 34,2008

15. Hoffman, A.S. Hydrogels for biomedical applications. Adv Drug Deliv Rev 54, 3, 2002.

16. Lee, K.Y., and Mooney, D.J. Hydrogels for tissue engineering. Chem Rev 101, 1869, 2001.

17. Kretlow, J.D., Klouda, L., and Mikos, A.G. Injectable matrices and scaffolds for drug delivery in tissue engineering. Adv Drug Deliv Rev 59, 263, 2007.

18. Mano, J.F., Sousa, R.A., Boesel, L.F., Neves, N.M., and Reis, R.L. Bioinert, biodegradable and injectable polymeric matrix composites for hard tissue replacement: state of the art and recent developments. Compos Sci Technol 64, 789, 2004.

19. Griffith, L.G. Polymeric biomaterials. Acta Mater 48, 263, 2000.

20. Rezwan, K., Chen, Q.Z., Blaker, J.J., and Boccaccini, A.R. Biodegradable and bioactive porous polymer/inorganic composite scaffolds for bone tissue engineering. Biomaterials 27, 3413, 2006.

21. Neumann, M., and Epple, M. Composites of calcium phosphate and polymers as bone substitution materials. Eur J Trauma 32, 125, 2006.

22. Driessens, F.C.M., Boltong, M.G., Bermúdez, O., Planell, J.A., Ginebra, M.P., and Fernandez, E. Effective formulations for the preparation of calcium phosphate bone cements. J Mater Sci Mater Med 5, 164, 1994.

23. Seal, B.L., Otero, T.C., and Panitch, A. Polymeric biomaterials for tissue and organ regeneration. Mater Sci Eng R Rep 34, 147, 2001.

24. Temenoff, J.S., and Mikos, A.G. Injectable biodegradable materials for orthopedic tissue engineering. Biomaterials 21, 2405, 2000

25. Jeong, B., Kim, S.W., and Bae, Y.H. Thermosensitive sol-gel reversible hydrogels. Adv Drug Deliv Rev 54, 37, 2002.

26. Gutowska, A., Byeongmoon, J., and Jasionowski, M. Injectable gels for tissue engineering. Anat $\operatorname{Rec}$ 263, 342, 2001.

27. $\mathrm{Yu}, \mathrm{L}$., and Ding, J. Injectable hydrogels as unique biomedical materials. Chem Soc Rev 37, 1473, 2008.

28. Mano, J.F., Silva, G.A., Azevedo, H.S., Malafaya, P.B., Sousa, R.A., Silva, S.S., Boesel, L.F., Oliveira, J.M., Santos, T.C., Marques, A.P., Neves, N.M., and Reis, R.L. Natural origin biodegradable systems in tissue engineering and regenerative medicine: present status and some moving trends. J R Soc Interface 4, 999, 2007.

29. Cao, W., and Hench, L.L. Bioactive materials. Ceram Int 22, 493, 1996.

30. Rea, S.M., Best, S.M., and Bonfield, W. Bioactivity of ceramic-polymer composites with varied composition and surface topography. J Mater Sci Mater Med 15, 997, 2004.

31. Ara, M., Watanabe, M., and Imai, Y. Effect of blending calcium compounds on hydrolytic degradation of poly (-lactic acid-co-glycolic acid). Biomaterials 23, 2479, 2002.

32. Schiller, C., and Epple, M. Carbonated calcium phosphates are suitable $\mathrm{pH}$-stabilising fillers for biodegradable polyesters. Biomaterials 24, 2037, 2003.

33. Kamitakahara, M., Ohtsuki, C., and Miyazaki, T. Review paper: behavior of ceramic biomaterials derived from tricalcium phosphate in physiological condition. J Biomater Appl 23, 197, 2008.

34. Dorozhkin, S., and Epple, M. Biological and medical significance of calcium phosphates. Angew Chem Int Ed Engl 41, 3130, 2002. 
35. Dorozhkin, S. Calcium orthophosphates. J Mater Sci 42, 1061, 2007.

36. Tadic, D., and Epple, M. A thorough physicochemical characterisation of 14 calcium phosphate-based bone substitution materials in comparison to natural bone. Biomaterials 25, 987, 2004.

37. Hench, L.L. Sol-gel materials for bioceramic applications. Curr Opin Solid State Mater Sci 2, 604, 1997.

38. Jones, J.R., Ehrenfried, L.M., and Hench, L.L. Optimising bioactive glass scaffolds for bone tissue engineering. Biomaterials 27, 964, 2006.

39. Ohtsuki, C., Kokubo, T., and Yamamuro, T. Mechanism of apatite formation on $\mathrm{CaOSiO}_{2} \mathrm{P}_{2} \mathrm{O}_{5}$ glasses in a simulated body fluid. J Noncryst Solids 143, 84, 1992.

40. Takadama, H., Kim, H.M., Kokubo, T., and Nakamura, T. TEM-EDX study of mechanism of bonelike apatite formation on bioactive titanium metal in simulated body fluid. J Biomed Mater Res 57, 441, 2001.

41. Karlsson, K.H., Fröberg, K., and Ringbom, T. A structural approach to bone adhering of bioactive glasses. J Noncryst Solids 112, 69, 1989.

42. Rhee, S.H., Lee, S.J., and Tanaka, J. Synergistic effect of silanol group and calcium ion in chitosan membrane on apatite forming ability in simulated body fluid. J Biomater Sci Polym Ed 17, 357, 2006.

43. Swetha, M., Sahithi, K., Moorthi, A., Srinivasan, N., Ramasamy, K., and Selvamurugan, N. Biocomposites containing natural polymers and hydroxyapatite for bone tissue engineering. Int J Biol Macromol 47, 1, 2010.

44. Cen, L., Liu, W., Cui, L., Zhang, W., and Cao, Y. Collagen tissue engineering: development of novel biomaterials and applications. Pediatr Res 63, 492, 2008.

45. Rho, J.-Y., Kuhn-Spearing, L., and Zioupos, P. Mechanical properties and the hierarchical structure of bone. Med Eng Phys 20, 92, 1998.

46. Lin, Y.-C., Tan, F.-J., Marra, K.G., Jan, S.-S., and Liu, D.-C. Synthesis and characterization of collagen/hyaluronan/ chitosan composite sponges for potential biomedical applications. Acta Biomater 5, 2591, 2009.

47. Giraud Guille, M.M., Mosser, G., Helary, C., and Eglin, D. Bone matrix like assemblies of collagen: from liquid crystals to gels and biomimetic materials. Micron 36, 602, 2005.

48. Song, J.-H., Kim, H.-E., and Kim, H.-W. Collagen-apatite nanocomposite membranes for guided bone regeneration. J Biomed Mater Res B Appl Biomater 83B, 248, 2007.

49. Zou, C., Weng, W., Deng, X., Cheng, K., Liu, X., Du, P., Shen, G., and Han, G. Preparation and characterization of porous $\beta$-tricalcium phosphate/collagen composites with an integrated structure. Biomaterials 26, 5276, 2005.

50. Wahl, D.A., and Czermuszka, J.T. Collagen-hydroxyapatite composites for hard tissue repair. Eur Cells Mater 11, 43, 2006.

51. Saffarzadeh, A., Gauthier, O., Bilban, M., Bagot D'Arc, M., and Daculsi, G. Comparison of two bone substitute biomaterials consisting of a mixture of fibrin sealant (Tisseel) and MBCP (TricOs) with an autograft in sinus lift surgery in sheep. Clin Oral Implants Res 20, 1133, 2009.

52. Weinand, C., Pomerantseva, I., Neville, C.M., Gupta, R., Weinberg, E., Madisch, I., Shapiro, F., Abukawa, H., Troulis, M.J., and Vacanti, J.P. Hydrogel-beta-TCP scaffolds and stem cells for tissue engineering bone. Bone 38, 555, 2006.

53. Le Nihouannen, D., Guehennec, L.L., Rouillon, T., Pilet, P., Bilban, M., Layrolle, P., and Daculsi, G. Micro-architecture of calcium phosphate granules and fibrin glue composites for bone tissue engineering. Biomaterials 27, 2716, 2006.

54. Tan, R., Niu, X., Gan, S., and Feng, Q. Preparation and characterization of an injectable composite. J Mater Sci Mater Med 20, 1245, 2009.

55. Turco, G., Marsich, E., Bellomo, F., Semeraro, S., Donati, I., Brun, F., Grandolfo, M., Accardo, A., and Paoletti, S. Alginate/hydroxyapatite biocomposite for bone ingrowth: a trabecular structure with high and isotropic connectivity. Biomacromolecules 10, 1575, 2009.

56. Shiraishi, N., Anada, T., Honda, Y., Masuda, T., Sasaki, K., and Suzuki, O. Preparation and characterization of porous alginate scaffolds containing various amounts of octacalcium phosphate (OCP) crystals. J Mater Sci Mater Med 21, 907, 2010.

57. Madhumathi, K., Sudheesh Kumar, P.T., Kavya, K.C., Furuike, T., Tamura, H., Nair, S.V., and Jayakumar, R. Novel chitin/nanosilica composite scaffolds for bone tissue engineering applications. Int J Biol Macromol 45, 289, 2009.

58. Lee, E.-J., Shin, D.-S., Kim, H.-E., Kim, H.-W., Koh, Y.-H., and Jang, J.-H. Membrane of hybrid chitosan-silica xerogel for guided bone regeneration. Biomaterials 30, 743, 2009.

59. Okada, M. Chemical syntheses of biodegradable polymers. Prog Polym Sci 27, 87, 2002.

60. Kim, B.S., and Mooney, D.J. Development of biocompatible synthetic extracellular matrices for tissue engineering. Trends Biotechnol 16, 224, 1998.

61. Nair, L.S., and Laurencin, C.T. Biodegradable polymers as biomaterials. Prog Polym Sci 32, 762, 2007.

62. Tessmar, J.K., and Gopferich, A.M. Customized PEG-derived copolymers for tissue-engineering applications. Macromol Biosci 7, 23, 2007.

63. Tan, H., DeFail, A.J., Rubin, J.P., Chu, C.R., and Marra, K.G. Novel multiarm PEG-based hydrogels for tissue engineering. J Biomed Mater Res A 92, 979, 2009.

64. Ruel-Gariépy, E., and Leroux, J.-C. In situ-forming hydrogels-review of temperature-sensitive systems. Eur J Pharm Biopharm 58, 409, 2004.

65. Fedorovich, N.E., Alblas, J., de Wijn, J.R., Hennink, W.E., Verbout, A.J., and Dhert, W.J.A. Hydrogels as extracellular matrices for skeletal tissue engineering: state-of-the-art and novel application in organ printing. Tissue Eng 13, 1905, 2007.

66. Sarvestani, A.S., He, X., and Jabbari, E. Effect of osteonectin-derived peptide on the viscoelasticity of hydrogel/ apatite nanocomposite scaffolds. Biopolymers 85, 370, 2007.

67. Sarvestani, A.S., He, X., and Jabbari, E. Osteonectin-derived peptide increases the modulus of a bone-mimetic nanocomposite. Eur Biophys J 37, 229, 2008.

68. Patel, M., Patel, K.J., Caccamese, J.F., Coletti, D.P., Sauk, J.J., and Fisher, J.P. Characterization of cyclic acetal hydroxyapatite nanocomposites for craniofacial tissue engineering. J Biomed Mater Res 94, 408, 2010.

69. Song, J., Xu, J., Filion, T., Saiz, E., Tomsia, A.P., Lian, J.B., Stein, G.S., Ayers, D.C., and Bertozzi, C.R. Elastomeric highmineral content hydrogel-hydroxyapatite composites for orthopedic applications. J Biomed Mater Res 89, 1098, 2009.

70. Li, C., Zheng, Y.-F., and Lou, X. Calcification capacity of porous pHEMA-TiO 2 composite hydrogels. J Mater Sci Mater Med 20, 2215, 2009.

71. Huang, J., Best, S.M., Brooks, R.A., Rushton, N., and Bonfield, W. In vitro evaluation of nanosized carbonate-substituted hydroxyapatite and its polyhydroxyethylmethacrylate nanocomposite. J Biomed Mater Res 87, 598, 2008. 
72. Costantini, A., Luciani, G., Annunziata, G., Silvestri, B., and Branda, F. Swelling properties and bioactivity of silica gel/ pHEMA nanocomposites. J Mater Sci Mater Med 17, 319, 2006.

73. Du, C., Cui, F.Z., Zhang, W., Feng, Q.L., Zhu, X.D., and de Groot, K. Formation of calcium phosphate/collagen composites through mineralization of collagen matrix. J Biomed Mater Res 50, 518, 2000.

74. Furuichi, K., Oaki, Y., Ichimiya, H., Komotori, J., and Imai, H. Preparation of hierarchically organized calcium phosphate-organic polymer composites by calcification of hydrogel. Sci Technol Adv Mater 7, 219, 2006.

75. Hutchens, S.A., Benson, R.S., Evans, B.R., O'Neill, H.M., and Rawn, C.J. Biomimetic synthesis of calcium-deficient hydroxyapatite in a natural hydrogel. Biomaterials 27, 4661, 2006.

76. Madhumathi, K., Shalumon, K.T., Rani, V.V.D., Tamura, H., Furuike, T., Selvamurugan, N., Nair, S.V., and Jayakumar, R. Wet chemical synthesis of chitosan hydrogel-hydroxyapatite composite membranes for tissue engineering applications. Int J Biol Macromol 45, 12, 2009.

77. Hong, L., Wang, Y.L., Jia, S.R., Huang, Y., Gao, C., and Wan, Y.Z. Hydroxyapatite/bacterial cellulose composites synthesized via a biomimetic route. Mater Lett 60, 1710, 2006.

78. Kim, C.W., Kim, S.E., Kim, Y.W., Lee, H.J., Choi, H.W., Chang, J.H., Choi, J., Kim, K.J., Shim, K.B., Jeong, Y.-K., and Lee, S.C. Fabrication of hybrid composites based on biomineralization of phosphorylated poly(ethylene glycol) hydrogels. J Mater Res 24, 50, 2009.

79. Golub, E.E. Role of matrix vesicles in biomineralization. Biochim Biophys Acta 1790, 1592, 2009.

80. Anderson, H.C. Molecular biology of matrix vesicles. Clin Orthop Relat Res 314, 266, 1995.

81. Liu, G., Zhao, D., Tomsia, A.P., Minor, A.M., Song, X., and Saiz, E. Three-dimensional biomimetic mineralization of dense hydrogel templates. J Am Chem Soc 131, 9937, 2009.

82. Pederson, A.W., Ruberti, J.W., and Messersmith, P.B. Thermal assembly of a biomimetic mineral/collagen composite. Biomaterials 24, 4881, 2003.

83. Westhaus, E., and Messersmith, P.B. Triggered release of calcium from lipid vesicles: a bioinspired strategy for rapid gelation of polysaccharide and protein hydrogels. Biomaterials 22, 453, 2001.

84. Golub, E.E., and Boesze-Battaglia, K. The role of alkaline phosphatase in mineralization. Curr Opin Orthop 18, 444, 2007.

85. Warnes, T.W. Alkaline phosphatase. Gut 13, 926, 1972.

86. Orimo, $\mathrm{H}$. The mechanism of mineralization and the role of alkaline phosphatase in health and disease. J Nippon Med Sch 77, 4, 2010.

87. de Jonge, L.T., Leeuwenburgh, S.C.G., van den Beucken, J., Wolke, J.G.C., and Jansen, J.A. Electrosprayed enzyme coatings as bioinspired alternatives to bioceramic coatings for orthopedic and oral implants. Adv Funct Mat 19, 755, 2009.

88. Osathanon, T., Giachelli, C.M., and Somerman, M.J. Immobilization of alkaline phosphatase on microporous nanofibrous fibrin scaffolds for bone tissue engineering. Biomaterials 30, 4513, 2009.

89. Filmon, R., Basle, M.F., Barbier, A., and Chappard, D. Poly(2-hydroxy ethyl methacrylate)-alkaline phosphatase: a composite biomaterial allowing in vitro studies of bisphosphonates on the mineralization process. J Biomater Sci Polym Ed 11, 849, 2000.
90. Spoerke, E.D., Shawn, G.A., and Stupp, S.I. Enzyme directed templating of artificial bone mineral. Adv Mater 21, 425, 2009.

91. Hunter, G.K., Hauschka, P.V., Poole, A.R., Rosenberg, L.C., and Goldberg, H.A. Nucleation and inhibition of hydroxyapatite formation by mineralized tissue proteins. Biochem J 317 (Pt 1), 59, 1996.

92. Baht, G.S., Hunter, G.K., and Goldberg, H.A. Bone sialoprotein-collagen interaction promotes hydroxyapatite nucleation. Matrix Biol 27, 600, 2008.

93. Hunter, G.K., Kyle, C.L., and Goldberg, H.A. Modulation of crystal formation by bone phosphoproteins: structural specificity of the osteopontin-mediated inhibition of hydroxyapatite formation. Biochem J 300 (Pt 3), 723, 1994.

94. Stancu, I.C., Filmon, R., Cincu, C., Marculescu, B., Zaharia, C., Tourmen, Y., Basle, M.F., and Chappard, D. Synthesis of methacryloyloxyethyl phosphate copolymers and in vitro calcification capacity. Biomaterials 25, 205, 2004.

95. Nuttelman, C.R., Benoit, D.S.W., Tripodi, M.C., and Anseth, K.S. The effect of ethylene glycol methacrylate phosphate in PEG hydrogels on mineralization and viability of encapsulated hMSCs. Biomaterials 27, 1377, 2006.

96. Wang, D.-A., Williams, C.G., Yang, F., Cher, N., Lee, H., and Elisseeff, J.H. Bioresponsive phosphoester hydrogels for bone tissue engineering. Tissue Eng Part A 11, 201, 2005.

97. Filmon, R., Grizon, F., Baslé, M.F., and Chappard, D. Effects of negatively charged groups (carboxymethyl) on the calcification of poly(2-hydroxyethyl methacrylate). Biomaterials 23, 3053, 2002.

98. Garrett, Q., Chatelier, R.C., Griesser, H.J., and Milthorpe, B.K. Effect of charged groups on the adsorption and penetration of proteins onto and into carboxymethylated poly(HEMA) hydrogels. Biomaterials 19, 2175, 1998.

99. Song, J., Saiz, E., and Bertozzi, C.R. A new approach to mineralization of biocompatible hydrogel scaffolds: an efficient process toward 3-dimensional bonelike composites. J Am Chem Soc 125, 1236, 2003.

100. Song, J., Malathong, V., and Bertozzi, C.R. Mineralization of synthetic polymer scaffolds: a bottom-up approach for the development of artificial bone. J Am Chem Soc 127, 3366, 2005.

101. Ho, E., Lowman, A., and Marcolongo, M. In situ apatite forming injectable hydrogel. J Biomed Mater Res 83A, 249, 2007.

102. Ho, E., Lowman, A., and Marcolongo, M. Synthesis and characterization of an injectable hydrogel with tunable mechanical properties for soft tissue repair. Biomacromolecules 7, 3223, 2006.

103. Sugino, A., Miyazaki, T., and Ohtsuki, C. Apatite-forming ability of polyglutamic acid hydrogels in a body-simulating environment. J Mater Sci Mater Med 19, 2269, 2008.

104. Baht, G.S., Hunter, G.K., and Goldberg, H.A. Bone sialoprotein-collagen interaction promotes hydroxyapatite nucleation. Matrix Biol 27, 600, 2008.

105. Chirila, T.V., Minamisawa, T., Keen, I., and Shiba, K. Effect of motif-programmed artificial proteins on the calcium uptake in a synthetic hydrogel. Macromol Biosci 9, 959, 2009.

106. Gungormus, M., Branco, M., Fong, H., Schneider, J.P., Tamerler, C., and Sarikaya, M. Self assembled bi-functional peptide hydrogels with biomineralization-directing peptides. Biomaterials 31, 7266, 2010.

107. Saito, N., Okada, T., Horiuchi, H., Ota, H., Takahashi, J., Murakami, N., Nawata, M., Kojima, S., Nozaki, K., and Takaoka, K. Local bone formation by injection of recom- 
binant human bone morphogenetic protein-2 contained in polymer carriers. Bone 32, 381, 2003.

108. Onishi, T., Ishidou, Y., Nagamine, T., Yone, K., Imamura, T., Kato, M., Sampath, T.K., ten Dijke, P., and Sakou, T. Distinct and overlapping patterns of localization of bone morphogenetic protein (BMP) family members and a BMP type II receptor during fracture healing in rats. Bone 22, 605, 1998.

109. Vaccaro, A.R., Chiba, K., Heller, J.G., Patel, T.C., Thalgott, J.S., Truumees, E., Fischgrund, J.S., Craig, M.R., Berta, S.C., and Wang, J.C. Bone grafting alternatives in spinal surgery. Spine J 2, 206, 2002.

110. Takaoka, K., Koezuka, M., and Nakahara, H. Telopeptidedepleted bovine skin collagen as a carrier for bone morphogenetic protein. J Orthop Res 9, 902, 1991.

111. Hayashi, C., Hasegawa, U., Saita, Y., Hemmi, H., Hayata, T., Nakashima, K., Ezura, Y., Amagasa, T., Akiyoshi, K., and Noda, M. Osteoblastic bone formation is induced by using nanogel-crosslinking hydrogel as novel scaffold for bone growth factor. J Cell Physiol 220, 1, 2009.

112. Park, H., Temenoff, J.S., Holland, T.A., Tabata, Y., and Mikos, A.G. Delivery of TGF-B1 and chondrocytes via injectable, biodegradable hydrogels for cartilage tissue engineering applications. Biomaterials 26, 7095, 2005.

113. Akagawa, Y., Kubo, T., Koretake, K., Hayashi, K., Doi, K., Matsuura, A., Morita, K., Takeshita, R., Yuan, Q., and Tabata, Y. Initial bone regeneration around fenestrated implants in Beagle dogs using basic fibroblast growth factor-gelatin hydrogel complex with varying biodegradation rates. J Prosthodont Res 53, 41, 2009.

114. Young, S., Patel, Z.S., Kretlow, J.D., Murphy, M.B., Mountziaris, P.M., Baggett, L.S., Ueda, H., Tabata, Y., Jansen, J.A., Wong, M., and Mikos, A.G. Dose effect of dual delivery of vascular endothelial growth factor and bone morphogenetic protein- 2 on bone regeneration in a rat critical-size defect model. Tissue Eng Part A 15, 2347, 2009.

115. Place, E.S., George, J.H., Williams, C.K., and Stevens, M.M. Synthetic polymer scaffolds for tissue engineering. Chem Soc Rev 38, 1139, 2009.

116. Jo, S., Shin, H., and Mikos, A.G. Modification of oligo(poly(ethylene glycol) fumarate) macromer with a GRGD peptide for the preparation of functionalized polymer networks. Biomacromolecules 2, 255, 2001.

117. Drury, J.L., and Mooney, D.J. Hydrogels for tissue engineering: scaffold design variables and applications. Biomaterials 24, 4337, 2003.

118. Payne, R.G., Yaszemski, M.J., Yasko, A.W., and Mikos, A.G. Development of an injectable, in situ crosslinkable, degradable polymeric carrier for osteogenic cell populations. Part 1. Encapsulation of marrow stromal osteoblasts in surface crosslinked gelatin microparticles. Biomaterials 23, 4359, 2002.

119. Park, H., Temenoff, J.S., Tabata, Y., Caplan, A.I., and Mikos, A.G. Injectable biodegradable hydrogel composites for rabbit marrow mesenchymal stem cell and growth factor delivery for cartilage tissue engineering. Biomaterials 28, 3217, 2007.
120. Kaihara, S., Matsumura, S., and Fisher, J.P. Cellular responses to degradable cyclic acetal modified PEG hydrogels. J Biomed Mater Res 90A, 863, 2009.

121. Bernhardt, A., Despang, F., Lode, A., Demmler, A., Hanke, T., and Gelinsky, M. Proliferation and osteogenic differentiation of human bone marrow stromal cells on alginategelatine-hydroxyapatite scaffolds with anisotropic pore structure. J Tissue Eng Regen Med 3, 54, 2009.

122. Keskar, V., Marion, N.W., Mao, J.J., and Gemeinhart, R.A. In vitro evaluation of macroporous hydrogels to facilitate stem cell infiltration, growth, and mineralization. Tissue Eng Part A 15, 1695, 2009.

123. Salinas, C.N., and Anseth, K.S. Mesenchymal stem cells for craniofacial tissue regeneration: designing hydrogel delivery vehicles. J Dental Res 88, 681, 2009.

124. Wang, D.A., Williams, C.G., Yang, F., Cher, N., Lee, H., and Elisseeff, J.H. Bioresponsive phosphoester hydrogels for bone tissue engineering. Tissue Eng 11, 201, 2005.

125. Li, Q., Wang, J., Shahani, S., Sun, D.D., Sharma, B., Elisseeff, J.H., and Leong, K.W. Biodegradable and photocrosslinkable polyphosphoester hydrogel. Biomaterials 27, 1027, 2006.

126. Shin, H., Jo, S., and Mikos, A.G. Modulation of marrow stromal osteoblast adhesion on biomimetic oligopoly(ethylene glycol) fumarate hydrogels modified with Arg-GlyAsp peptides and a poly(ethyleneglycol) spacer. J Biomed Mater Res 61, 169, 2002.

127. Chun, C., Lim, H.J., Hong, K.Y., Park, K.H., and Song, S.C. The use of injectable, thermosensitive poly(organophosphazene)-RGD conjugates for the enhancement of mesenchymal stem cell osteogenic differentiation. Biomaterials 30, 6295, 2009.

128. Zhang, L., Rakotondradany, F., Myles, A.J., Fenniri, H., and Webster, T.J. Arginine-glycine-aspartic acid modified rosette nanotube-hydrogel composites for bone tissue engineering. Biomaterials 30, 1309, 2009.

129. Hunt, N.C., and Grover, L.M. Cell encapsulation using biopolymer gels for regenerative medicine. Biotech Lett 32, 733, 2010.

130. Schmidt, J.J., Rowley, J., and Kong, H.J. Hydrogels used for cell-based drug delivery. J Biomed Mater Res Part A 87, 1113, 2008.

Address correspondence to: John A. Jansen, D.D.S., Ph.D.

Department of Biomaterials Radboud University Nijmegen Medical Center P.O. BOX 9101 6500 HB Nijmegen The Netherlands

E-mail: j.jansen@dent.umcn.nl

Received: August 5, 2010

Accepted: August 23, 2010

Online Publication Date: September 29, 2010 
